\title{
Divergence among species and populations of Mediterranean pines in biomass allocation of seedlings grown under two watering regimes
}

\author{
Marìa Regina CHAMBEL, José CLIMENT, Ricardo Alía* \\ Instituto Nacional de Investigación y Tecnología Agraria y Alimentaria (INIA), Apto 8111, 28080 Madrid, Spain
}

(Received 27 February 2006; accepted 4 April 2006)

\begin{abstract}
Seedlings of four populations each of Pinus pinaster, P. halepensis, P. canariensis and P. pinea were grown in controlled conditions to evaluate both inter- and intra-specific differences in response to watering. We submitted half of the plants to a moderate water stress and after 22 weeks, we recorded height, stem diameter and root, stem and leaves dry weight. Patterns and amounts of phenotypic changes, including changes in biomass allocation, were analysed. We found a scant response in P. canariensis, P. pinaster and P. halepensis presented high population divergence for phenotypic changes, and P. pinea showed marked allocational shifts and no population divergence. The phenotypic changes observed within species are interpreted as a plastic response. The variation encountered within P. halepensis and P. pinaster may be indicative of specialisation to either resource-rich or resource-poor habitats, being populations from favourable sites more plastic. $P$. pinea exhibited a very uniform plastic response, indicating generalist behaviour.
\end{abstract}

phenotypic changes / early testing / pine / drought stress / ontogeny

Résumé - Divergences parmi les espèces et populations de pins méditerranéens pour l'allocation de biomasse chez des semis poussant sous deux régimes d'alimentation hydrique. Des semis de quatre populations de Pinus pinaster, de $P$. halepensis, de $P$. canariensis, et de $P$. pinea ont été élevés en conditions contrôlées pour évaluer au niveau inter- et intra-spécifique les différences de réponse au régime d'alimentation hydrique. Nous avons soumis la moitié des plants à un stress hydrique modéré et après 22 semaines nous avons mesuré leur hauteur, le diamètre de la tige et des racines, le poids sec de la tige et des feuilles. Les modèles et l'importance des changements phénotypiques, incluant les variations d'allocation de biomasse ont été analysés. Nous avons trouvé une faible réponse pour $P$. canariensis; $P$. pinaster et $P$. halepensis ont présenté une importante divergence des populations au plan des changements phénotypiques, et $P$. pinea a montré une modification sensible au plan de l'allocation de biomasse sans divergence de population. Les changements phénotypiques observés chez les espèces ont été interprétés comme une réponse en terme de plasticité. Les variations rencontrées chez $P$. halepensis et $P$. pinaster peuvent être l'indice d'une spécialisation pour des habitats riches ou pauvres en terme de ressources. $P$. pinea a présenté une plasticité uniforme de réponse, révélant un comportement généraliste.

changements phénotypiques / test précoce / stress hydrique / ontogénie

\section{INTRODUCTION}

How do plants modify their phenotypes according to environment? This question has been the focus of interest in science in general and in forest science in particular during the last two hundred years [23]. In most cases, those phenotypic changes due to genotype by environment interactions were considered as a source of error in most breeding and genetic evaluation programs, and several techniques have been developed to deal with this topic [20,38,47]. However, recently new perspectives were open to the analyses of those changes, when seen from a more general point of view, and taking into consideration different evolutionary implications. In this framework, considerable research efforts are being dedicated to the study of phenotypic plasticity, i.e. the ability of a genotype (in a broad sense: species, population, family or clone, see [37] for a general discussion on the topic) to alter its morphology and physiology in response to changes in the environmental conditions $[36,40]$. These changes are not inherently adaptive; in particular those related to resource limitation might represent inevitable responses of the organisms [10,28,51]. In fact, individuals faced with low resource levels during growth inevitably grow less. Nevertheless, phenotypic responses to different environments may also include specific developmental and functional adjustments that increase fitness in those environments $[7,13,27,44,49]$. According to the optimal partitioning theory, plants respond to stressful environmental conditions by shifting carbon allocation to the organs collecting the most limiting resource, a form of plasticity conducive to growth maximization $[5,11,42]$. However adjustments in biomass allocation also occur as a natural consequence of growth and development (ontogenetic drift sensu Evans [12]), reflecting a shift in plant priorities along an ontogenetic trajectory [50]. In many cases, developmental stage and environment alter the functional relationship between traits [33]. As a consequence, conclusions regarding morphological adjustments in response to a given stress treatment may differ

\footnotetext{
* Corresponding author: alia@inia.es
} 
Table I. Identification, location and relevant ecological features of the populations used in the present study.

\begin{tabular}{|c|c|c|c|c|c|c|c|}
\hline Species & Population (code) & Latitude & Longitude & Altitude (m) & $\begin{array}{c}\text { Annual } \\
\text { rainfall } \\
(\mathrm{mm})\end{array}$ & $\begin{array}{c}\text { Summer } \\
\text { rainfall } \\
(\mathrm{mm})^{1}\end{array}$ & $\begin{array}{c}\text { Growth } \\
\text { conditions }\end{array}$ \\
\hline & Arenas de S. Pedro (PR-AR ) & $40^{\circ} 12^{\prime} \mathrm{N}$ & $05^{\circ} 06^{\prime} \mathrm{W}$ & 750 & 1190 & 105 & $\mathrm{~F}$ \\
\hline Pinus & Cómpeta (PR-CP) & $36^{\circ} 51^{\prime} \mathrm{N}$ & $03^{\circ} 55^{\prime} \mathrm{W}$ & 900 & 700 & 24 & $\mathrm{U}$ \\
\hline \multirow[t]{3}{*}{ pinaster } & Leiria (PR-LE) & $39^{\circ} 45^{\prime} \mathrm{N}$ & $08^{\circ} 55^{\prime} \mathrm{W}$ & 60 & 910 & 50 & $\mathrm{~F}$ \\
\hline & Coca (PR-CC) & $41^{\circ} 14^{\prime} \mathrm{N}$ & $04^{\circ} 31^{\prime} \mathrm{W}$ & 810 & 470 & 67 & $\mathrm{U}$ \\
\hline & Villa de Ves (PH-VV) & $39^{\circ} 10^{\prime} \mathrm{N}$ & $01^{\circ} 14^{\prime} \mathrm{W}$ & 850 & 490 & 90 & $\mathrm{~F}$ \\
\hline Pinus & North Euboia (PH-NE) & $38^{\circ} 59^{\prime} \mathrm{N}$ & $23^{\circ} 30^{\prime} \mathrm{E}$ & 40 & 674 & 67 & $\mathrm{~F}$ \\
\hline \multirow[t]{3}{*}{ halepensis } & Alcantud (PH-AL) & $40^{\circ} 34^{\prime} \mathrm{N}$ & $02^{\circ} 19^{\prime} \mathrm{W}$ & 950 & 660 & 94 & $\mathrm{~F}$ \\
\hline & Ses Salines (PH-SS) & $39^{\circ} 17^{\prime} \mathrm{N}$ & $03^{\circ} 02^{\prime} \mathrm{E}$ & 10 & 300 & 27 & $\mathrm{U}$ \\
\hline & Vilaflor (PC-VI) & $28^{\circ} 11^{\prime} \mathrm{N}$ & $16^{\circ} 38^{\prime} \mathrm{W}$ & 2100 & 450 & 1 & $\mathrm{U}$ \\
\hline Pinus & Barlovento (PC-BA) & $28^{\circ} 47^{\prime} \mathrm{N}$ & $17^{\circ} 51^{\prime} \mathrm{W}$ & 1900 & 950 & 12 & $\mathrm{~F}$ \\
\hline \multirow[t]{3}{*}{ canariensis } & Punta Gorda (PC-PG) & $28^{\circ} 47^{\prime} \mathrm{N}$ & $17^{\circ} 58^{\prime} \mathrm{W}$ & 800 & 550 & 3 & $\mathrm{~F}$ \\
\hline & Tirajana $(\mathrm{PC}-\mathrm{TI})$ & $27^{\circ} 53^{\prime} \mathrm{N}$ & $15^{\circ} 36^{\prime} \mathrm{W}$ & 950 & 300 & 0 & $\mathrm{U}$ \\
\hline & Tordesillas (PA-TO) & $41^{\circ} 30^{\prime} \mathrm{N}$ & $04^{\circ} 57^{\prime} \mathrm{W}$ & 680 & 470 & 75 & $\mathrm{U}$ \\
\hline Pinus & Tarazona de la Mancha (PA-TM) & $39^{\circ} 17^{\prime} \mathrm{N}$ & $01^{\circ} 55^{\prime} \mathrm{W}$ & 700 & 400 & 56 & $\mathrm{U}$ \\
\hline \multirow[t]{2}{*}{ pinea } & Cartaya (PA-CA) & $37^{\circ} 22^{\prime} \mathrm{N}$ & $07^{\circ} 11^{\prime} \mathrm{W}$ & 82 & 510 & 18 & $\mathrm{~F}$ \\
\hline & Palafrugell (PA-PL) & $41^{\circ} 57^{\prime} \mathrm{N}$ & $03^{\circ} 06^{\prime} \mathrm{W}$ & 100 & 660 & 94 & $\mathrm{~F}$ \\
\hline
\end{tabular}

${ }^{1}$ Summer months include June, July and August. ${ }^{2} \mathrm{~F}=$ Favourable growth conditions, $\mathrm{U}=$ Unfavourable growth conditions, based on ecological data from [12].

dramatically if ontogenetic changes in phenotypic expression are also taken into consideration $[9,19,29,39,46]$.

Still, little is known about the trade-offs between phenotypic changes and ecotypic differentiation in long-lived organisms that must face a changing environment. Mediterranean pines sensu Klaus [22] (Pinus pinaster, P. halepensis, $P$. brutia, $P$. pinea, $P$. canariensis, $P$. roxburghii and $P$. heldreichii) constitute an interesting group of species to address these questions. They form a well-defined phylogenetic group [26], exhibit marked differences in life-history traits [43], have different evolutionary histories, and presently occupy different ecological niches [4], with marked differences in water availability [14].

The objectives of this research were to check for differences among closely related species and populations within species in the degree and nature of morphological changes in response to watering regimes at early developmental stages. Our work hypothesis is that phenotypic change is a trait on itself, different from the trait under evaluation in each environment, and thus subject of genetic control at different organization levels $[7,35,37]$.

To attain the proposed objectives, we used four Mediterranean pines with different degrees of drought tolerance, each represented by four populations. We examined growth and morphology of seedlings of these four species grown under two water regimes and assessed the effect of water availability on growth rates and on the allometric relationships between biomass compartments independently from the effect of ontogenetic drift. Furthermore, to avoid confounding the effect of watering treatments with ontogenetic shifts in biomass allocation, besides using plant size as a proxy to ontogeny in allometric analysis, we also used a categorical morphological scale to characterise the ontogenetic stage of each seedling. Based on our results, we discuss the use of short-term experiments under controlled conditions to evaluate phenotypic changes and the relationship among our observations and phenotypic plasticity facing drought.

\section{MATERIAL AND METHODS}

\subsection{Plant material}

We used four Mediterranean pine species (Pinus pinaster, $P$. halepensis, $P$. canariensis and $P$. pinea), each represented by four populations. The seeds were collected in natural populations, selected to cover a wide range of environments, including material from populations with both favourable and unfavourable environmental or genetic growth conditions (Tab. I). So as to draw conclusions at the population level and ensure repeatability of the experiment, we used an equilibrated mix of seeds collected from random samples of 25 to 30 open-pollinated individuals per population, separated by a minimum of $100 \mathrm{~m}$ to reduce consanguinity.

\subsection{Experimental design}

The study was conducted in a growth chamber with controlled temperature and photoperiod. After seed germination, we 


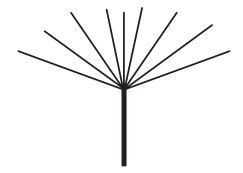

0

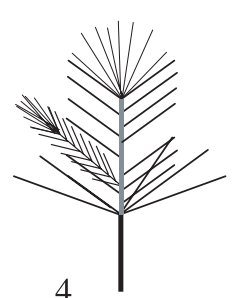

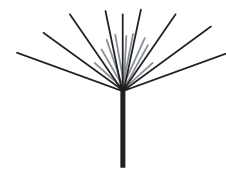

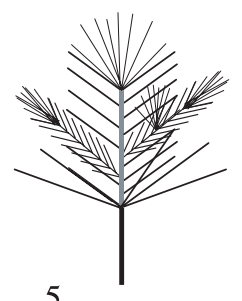

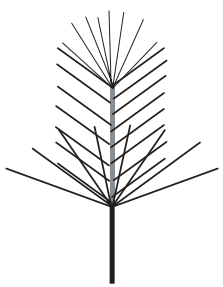

2

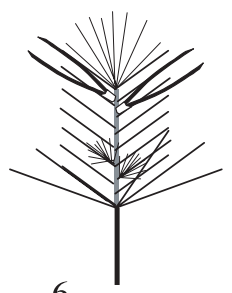

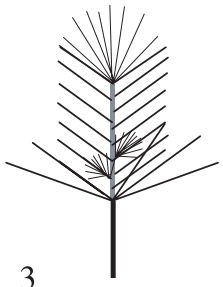

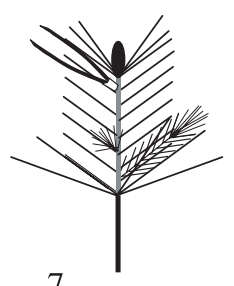

Figure 1. Ontogenetic scores. (0) Cotyledonary stage, (1) emergence of the epicotyl rosette, (2) epicotyl elongation, (3) formation of axillary buds, (4) elongation of axillary long shoots, (5) formation of secondary axillary long shoots, (6) occurrence of dwarf shoots, (7) formation of a terminal bud.

transplanted thirty-six seedlings per population into $250 \mathrm{~cm}^{3}$ individual plastic containers, filled with peat and vermiculite $(4: 1, \mathrm{v} / \mathrm{v})$ and placed them inside the growth chamber. Half of the seedlings (18 per population) were randomly assigned to each of the waterstress treatments. A split-split plot design (population within species within water stress treatment), with two replicates of nine seedlings each, was used to control the effect of competition between neighbours and to compensate for the light intensity gradient across the chamber. Plants were maintained in the growth chamber for twentytwo weeks, following a protocol that included nine weeks of long photoperiod and high temperature, followed by a progressive decrease of both photoperiod and temperature to induce bud rest. Similar protocols have proven to significantly accelerate the maturation rate in maritime pine seedlings, leading to higher correlations with mature behaviour $[24,30]$. Plants were watered to field capacity approximately every two days, except during the water stress treatment, as detailed below. The water stress treatment started in the ninth week from transplant and lasted for six weeks, coinciding with the period of high temperature. During this period, the water supply was withdrawn from half of the plants until the water content of each individual container reached $30 \%$ of field capacity (determined by weight). This watering level was maintained approximately constant until the end of the stress period. The remaining plants were watered as described previously.

Seedling height was measured before and after the water stress period, and height growth during the interval (HGD) was computed both for stressed and non-stressed plants. After twenty-two weeks in the growth chamber, the plants were harvested. Diameter at root collar (D) and seedling height $(\mathrm{H})$ of every plant were measured. The seedlings were then partitioned into roots, stems, and leaves for biomass assessment [32]. All plant parts were oven-dried for $48 \mathrm{~h}$ at $80^{\circ} \mathrm{C}$ and then weighted. Dry weights of leaves (LDW), stems (SDW) and roots (RDW) were obtained and total dry weight (TDW) was computed from these values.

Shoot ontogeny was followed throughout the growth period, using a categorical, seven-level scale (Fig. 1), inspired by the works of Lester [25] and Williams [52] and based on the heteroblasty of shoot development [21]. Seedlings were assigned to the values 0 for the cotyledonary stage, (1) for emergence of the epicotyl rosette, (2) for epicotyl elongation, (3) for formation of axillary buds, (4) for elongation of axillary long shoots, (5) for formation of secondary axillary long shoots, (6) for occurrence of dwarf shoots (either on the main shoot or on lateral branches) and (7) for formation of a terminal bud. Higher scores reflected a more developed ontogenetic stage, allowing the comparison of different species, even when transition from level to level may not be continuous for all plants.

\subsection{Statistical analysis}

Growth (H, D, HGD) and biomass (TDW, RDW, SDW, LDW) variables were analysed with the general linear model approach to analysis of variance, with type III sum of squares, using SAS software. The model terms were fitted according to the hierarchical design of the experiment, considering populations as nested within species. In addition to this analysis, an ANOVA was carried out for each species separately to evaluate different trends at the population level. A significant effect of the water stress treatment in this analysis indicates the existence of phenotypic changes in response to drought for the trait considered and a significant genotype by environment interaction indicates the existence of differences among population or species for those changes [36]. Whenever the treatment factor was significant, the difference between mean phenotype of each species or population in the two environments considered was evaluated with a $t$-test.

Besides plotting standard reaction norms, we represented graphically the position of each population in the space defined by its mean phenotype under the water stress treatment (on the $x$-axis) and under the non-stress treatment (on the $y$-axis) following Pigliucci and Schlichting [31]. This way, each population is represented by a single point and, if the two axes are in the same scale, the main diagonal represents the line of null phenotypic change, that corresponds to a flat reaction norm and the tangent (slope) of the angle $\alpha$, formed between the line connecting each point to the origin and the $x$-axis 
can be interpreted as an index quantifying phenotypic change. The main advantage of this index, when compared to the most common methods based on the difference between mean phenotypic values in each environment (e.g. [34]), represented in this biplot by the orthogonal distance to the main diagonal, is that the slope is reflecting the change in relative terms, more significant from a biological point of view. Besides, this index also reflects the direction of the response (slope higher or lower than one), which has obvious biological relevance [48]. We will further refer to this index as angular phenotypic change index (APCI).

For the study of biomass allocation, we performed an allometric analysis through the regression of the natural logarithms of each biomass component (LDW, SDW and RDW) and the sum of the other two components $[29,32]$. Changes in allocational patterns were assessed by comparison of the slopes and intercepts corresponding to different watering levels [37]. When, for a given species or population within species, a strong linear relation between biomass compartments existed and the two lines of regression corresponding to the two water treatments overlapped, the slope of those lines will differ only if the water stress treatment caused significant changes in the relative growth rates of leaves, shoots and roots. Ontogenetic scores were analysed using logistic regression based on maximum likelihood estimations (procedure CATMOD of SAS).

\section{RESULTS}

\subsection{Inter-specific variation}

Species accounted for the highest proportion of the variability encountered in the analysis of most traits, as expected (Tab. II). Nevertheless, at this level, treatment effect was significant or highly significant for all the variables analysed. Species $\mathrm{x}$ treatment interaction was not significant either for height at the end of the experiment $(\mathrm{H})$ or for height growth during the drought period (HGD), but it was significant for diameter (D, $p<0.05)$ and most of the biomass-related traits (Tab. II). Considering the overall species effect (including the four populations together), the same ranking was found in both treatments for height and diameter growth, total biomass and leaf and stem biomass, with Pinus pinea attaining the highest values, followed by $P$. canariensis, $P$. pinaster and P. halepensis.

Height growth was significantly reduced during the drought period in the stressed plants of all four species $(p<0.001)$. At the end of the experiment, the seedlings of Pinus canariensis and Pinus pinaster showed no differences for biomass-related traits (TDW, RDW, SDW and LDW) while the other three species showed significant or highly significant reductions in both traits due to the imposed drought.

The allometric analysis revealed that the water stress induced changes in the proportions of biomass allocated to each plant compartment that were independent of plant size, i.e. the existence of changes in allocation patterns (differences on the slope, interception or both) in response to drought, in all four species. In general, these changes affected mainly roots and leaves. Different allometric trajectories for stems were found only in Pinus halepensis and P. canariensis, while the four
Table II. Proportion of the variance due to treatment, species and treatment by species interaction in the inter-specific analysis and significance of the corresponding $\mathrm{F}$ tests.

\begin{tabular}{llll}
\hline & Treatment & Species & Treatment $\times$ Species \\
\hline RDW & $0.281 * *$ & $0.100 * * *$ & $0.056 * *$ \\
SDW & $0.206 * * *$ & $0.614 * * *$ & 0.005 \\
LDW & $0.154 * * *$ & $0.523 * * *$ & $0.027 * * *$ \\
TDW & $0.208 * * *$ & $0.403 * * *$ & $0.024 * *$ \\
H & $0.208 * * *$ & $0.723 * * *$ & 0.010 \\
D & $0.162 * * *$ & $0.765 * * *$ & $0.011^{* *}$ \\
HGD & $0.637 * * *$ & $0.115^{* * *}$ & 0.004 \\
\hline
\end{tabular}

RDW: root dry weight; SDW: stem dry weight; LDW: leaf dry weight; TDW: total dry weight; $\mathrm{H}$ : height; $\mathrm{D}$ : diameter; HGD: height growth during drought. Significance levels $* * p<0.05$, $* * * p<0.001$.

species displayed allocational changes for leaves and all except $P$. canariensis for roots. Therefore, $P$. halepensis exhibited the highest degree of change in biomass allocation, followed by $P$. pinea, $P$. pinaster and finally by $P$. canariensis.

We found sharp differences among species for seedling maturation, as evaluated by the ontogenetic scores. Pinus pinaster attained the highest mean score, with a high proportion of seedlings bearing axillary dwarf shoots, followed by $P$. halepensis and $P$. pinea (not significantly different) and by $P$. canariensis, with a very low score. After 22 weeks, no plant attained the highest score on the scale, corresponding to the formation of a true terminal bud covered with cataphylls. Nevertheless, some $P$. pinaster seedlings showed a terminal rosette of short primary needles, closely resembling a terminal bud. Although statistically the ontogenetic scores of $P$. halepensis and $P$. pinea were not significantly different, individual plants of both groups were in fact very different. A small proportion of the $P$. halepensis seedlings formed dwarf shoots (level 6), while most were in level 5 and some remained in level 4. On the contrary, the relatively high score attained in $P$. pinea was exclusively due to the abundant secondary branching (level 5). The seedlings of this species formed the most uniform group with regard to ontogeny. In general, however, ontogenetic scores proved to be relatively stable within each species; only for $P$. halepensis we found significant differences among populations and water stress treatments $(p<0.001$ and $p<0.05$, respectively). The relationship between ontogenetic score and plant dry weight was different for each species and generally weak, especially in $P$. pinea $\left(r^{2}=0.02\right)$.

\subsection{Intra-specific variation}

Water stress treatment accounted for the highest proportion of the variability in Pinus pinaster in all traits except leaf biomass, while differences among populations were highly significant for all biomass components and for total height $(p<0.001)$. Population $\mathrm{x}$ treatment interaction was highly significant for all biomass related variables $(p<0.001)$, but 
Table III. Proportion of the variance due to treatment, population and treatment by population interaction in the intra-specific analysis and significance of the corresponding $\mathrm{F}$ tests.

\begin{tabular}{|c|c|c|c|c|c|c|c|c|c|c|c|c|}
\hline & \multicolumn{3}{|c|}{ P. pinaster } & \multicolumn{3}{|c|}{ P. halepensis } & \multicolumn{3}{|c|}{ P. canariensis } & \multicolumn{3}{|c|}{ P. pinea } \\
\hline & $\mathrm{T}$ & $\mathrm{P}$ & $\mathrm{T} \times \mathrm{P}$ & $\mathrm{T}$ & $\mathrm{P}$ & $\mathrm{T} \times \mathrm{P}$ & $\mathrm{T}$ & $\mathrm{P}$ & $\mathrm{T} \times \mathrm{P}$ & $\mathrm{T}$ & $\mathrm{P}$ & $\mathrm{T} \times \mathrm{P}$ \\
\hline $\mathrm{RDW}$ & $0.44 * * *$ & $0.20 * * *$ & $0.31 * * *$ & $0.74 * * *$ & $0.12 * * *$ & $0.11 * * *$ & 0.00 & 0.04 & 0.28 & $0.04 * *$ & 0.01 & 0.00 \\
\hline SDW & $0.51 * * *$ & $0.24 * * *$ & $0.21 * * *$ & $0.67 * * *$ & $0.16^{* * *}$ & $0.11 * * *$ & $0.58 * *$ & 0.16 & 0.14 & $0.13 * * *$ & 0.02 & 0.01 \\
\hline LDW & $0.25^{* *}$ & $0.31 * * *$ & $0.39 * * *$ & $0.71 * * *$ & $0.13 * * *$ & $0.13^{* * * *}$ & 0.00 & 0.19 & 0.32 & $0.19 * * *$ & 0.02 & 0.01 \\
\hline TDW & $0.35^{* * *}$ & $0.26 * * *$ & $0.34 * * *$ & $0.74 * * *$ & $0.12 * * *$ & $0.12 * * *$ & 0.01 & 0.13 & 0.31 & $0.13 * * *$ & 0.01 & 0.00 \\
\hline $\mathrm{H}$ & $0.69 * * *$ & $0.24 * * *$ & 0.02 & $0.51 * * *$ & $0.42 * * *$ & 0.03 & 0.11 & $0.24 * *$ & 0.01 & $0.83 * * *$ & 0.08 & 0.06 \\
\hline $\mathrm{D}$ & $0.46^{* *}$ & 0.16 & $0.28 * *$ & $0.86^{* * * *}$ & 0.02 & $0.05^{* *}$ & 0.45 & 0.30 & 0.09 & $0.16^{* * *}$ & 0.03 & 0.00 \\
\hline HGD & $0.91 * * *$ & 0.03 & 0.03 & $0.65^{* * *}$ & $0.15^{* * *}$ & 0.00 & $0.62 * * *$ & 0.03 & 0.02 & $0.62 * * *$ & $0.04 * * *$ & 0.01 \\
\hline
\end{tabular}

T: treatment; P: population; T $\times$ P: treatment $\times$ population; RDW: root dry weight; SDW: stem dry weight; LDW: leaf dry weight; TDW: total dry weight; H: height; D: diameter; HGD: height growth during drought. Significance levels $* * p<0.05, * * * p<0.001$.

not significant for height growth (Tab. III). This species displayed striking differences among populations in response to the drought stress treatment. Population PR-LE showed a remarkable change in total biomass and dry weight components (Tab. IV, Fig. 2), presenting the highest values of the angular phenotypic change index (APCI) found in this study (ranging from 2.71 for RDW to 1.31 for H, Fig. 2). On the contrary, populations PR-AR and PR-CP proved to be markedly stable for all traits under study (Tab. IV, Fig. 2). Population PR-CC exhibited significant changes only for height growth (reduced $\mathrm{H}$ in the stress treatment). In most cases, the response to drought was not reflected in different allometric relations between the biomass components. This species displayed significant differences in biomass allocational patterns only for stems in population PR-CP (different slopes) and for leaves in population PR-AR (different intercepts).

In Pinus halepensis, the water stress treatment accounted for the highest proportion of variability in all variables considered; population $\times$ treatment interaction followed trends similar to those described for P. pinaster (Tab. IV). Populations $\mathrm{PH}-\mathrm{VV}$ and PH-NE exhibited significant changes for all the growth and biomass related variables, with population $\mathrm{PH}-\mathrm{VV}$ reaching higher values of APCI in all cases (Tab. IV, Fig. 2). Population PH-AL exhibited significant reductions of diameter growth, TDW and RDW (APCI of 1.30 and 1.35, respectively), while population PH-SS showed no significant phenotypic changes for any of the traits considered. Contrasting with these results, population PH-AL showed the highest degree of change in biomass allocation, shifting allometric trajectories of all biomass compartments as a consequence of drought. Populations PH-NE and PH-SS exhibited significant changes in biomass allocation to stems while population PH-VV presented changes for leaves.

In the Canary Island pine, neither the water stress treatment nor the population accounted for significant proportions of the variance, with a few exceptions (SDW and HGD for treatment and $\mathrm{H}$ for population). No population $\times$ treatment interaction was found in this species. When considering the four populations separately, this species still displayed the lowest levels of phenotypic change. APCI values were in general amongst the lowest observed in the present study (Fig. 2), with significant differences between treatments only for RDW in population PC-PG. Nevertheless, populations PC-VI and PC-BA revealed shifts on the allometric trajectories for both leaves and roots, indicating that in this species the changes in biomass allocation patterns prevailed over the changes in growth variables.

The proportion of variability due to the water stress treatment in Pinus pinea was generally lower than that found in $P$. pinaster and $P$. halepensis, while the effect of population and that of population $\times$ treatment interaction were not significant in any case (Tab. IV). The populations of this species exhibited the highest levels of change in biomass allocation patterns, with the allometric curves fitted for roots and leaves overlapping completely and showing significantly different trajectories between drought treatments in all four populations (Fig. 3). Therefore, indicating that also in this species the allocational shifts overcome growth differences. Worthy of note is the fact that the direction of the response was identical in all cases; allocation to roots increased at the expenses of the above ground biomass components as a consequence of drought.

\section{DISCUSSION}

The present paper is focused on the morphological response of seedlings from close related species (and populations within species) to two contrasting watering regimes. The observed responses raise some questions worthy of a close look: the significance of those phenotypic changes from the perspective of the phenotypic plasticity of populations and the relationship among the observed changes and species differences regarding life history and ecology.

Until present, little information was available on the morphological changes induced by water stress during the initial developmental stages of Mediterranean pines and its variability within and between species. The direct comparison of the responses among species or populations within species poses some experimental difficulties related to the artificial design of the common stress treatments combined with the different tolerance of the species or populations under study. However, this is the only possible way to isolate genetic effects form 
Table IV. Means ( \pm standard errors) for biomass components and growth variables.

\begin{tabular}{|c|c|c|c|c|c|c|c|c|c|}
\hline & & & RDW (mg) & SDW (mg) & LDW (mg) & TDW (mg) & $\mathrm{H}(\mathrm{mm})$ & $\mathrm{D}(\mathrm{mm})$ & $\mathrm{HGD}(\mathrm{mm})$ \\
\hline \multirow{8}{*}{ P. pinaster } & \multirow{2}{*}{ PR-AR } & No-stress & $479 \pm 84$ & $188 \pm 31$ & $573 \pm 126$ & $1240 \pm 226$ & $59.5 \pm 6.6$ & $2.3 \pm 0.22$ & $31.9 \pm 4.4$ \\
\hline & & Stress & $490 \pm 49$ & $193 \pm 19$ & $816 \pm 78$ & $1499 \pm 141$ & $52.2 \pm 1.7$ & $2.4 \pm 0.13$ & $15.9 \pm 1.7$ \\
\hline & \multirow{2}{*}{ PR-CP } & No-stress & $471 \pm 101$ & $180 \pm 39$ & $704 \pm 121$ & $1355 \pm 251$ & $49.1 \pm 6.0$ & $2.3 \pm 0.15$ & $25.9 \pm 4.6$ \\
\hline & & Stress & $429 \pm 30$ & $162 \pm 13$ & $661 \pm 64$ & $1251 \pm 99$ & $39.3 \pm 2.6$ & $2.2 \pm 0.09$ & $19.2 \pm 2.1$ \\
\hline & \multirow{2}{*}{ PR-LE } & No-stress & $1058 \pm 96$ & $346 \pm 31$ & $1500 \pm 151$ & $2904 \pm 275$ & $66.6 \pm 4.0$ & $2.9 \pm 0.10$ & $36.0 \pm 2.0$ \\
\hline & & Stress & $391 \pm 52$ & $169 \pm 19$ & $667 \pm 72$ & $1226 \pm 136$ & $52.7 \pm 4.4$ & $2.1 \pm 0.13$ & $19.1 \pm 1.4$ \\
\hline & \multirow{2}{*}{ PR-CC } & No-stress & $508 \pm 134$ & $194 \pm 41$ & $714 \pm 207$ & $1416 \pm 377$ & $62.0 \pm 3.9$ & $2.3 \pm 0.23$ & $32.2 \pm 2.1$ \\
\hline & & Stress & $438 \pm 76$ & $132 \pm 18$ & $611 \pm 81$ & $1181 \pm 167$ & $47.3 \pm 5.0$ & $2.1 \pm 0.12$ & $21.1 \pm 2.8$ \\
\hline \multirow{8}{*}{ P. halepensis } & \multirow{2}{*}{ PH-VV } & No-stress & $704 \pm 51$ & $174 \pm 15$ & $876 \pm 66$ & $1754 \pm 128$ & $50.5 \pm 2.1$ & $2.3 \pm 0.08$ & $27.0 \pm 1.4$ \\
\hline & & Stress & $356 \pm 36$ & $99 \pm 8$ & $487 \pm 36$ & $942 \pm 76$ & $39.7 \pm 1.5$ & $1.7 \pm 0.05$ & $18.3 \pm 2.0$ \\
\hline & \multirow{2}{*}{ PH-NE } & No-stress & $760 \pm 71$ & $166 \pm 19$ & $787 \pm 61$ & $1714 \pm 147$ & $60.2 \pm 3.6$ & $2.2 \pm 0.09$ & $32.8 \pm 2.2$ \\
\hline & & Stress & $540 \pm 47$ & $120 \pm 9$ & $574 \pm 35$ & $1234 \pm 79$ & $49.8 \pm 2.8$ & $1.8 \pm 0.07$ & $23.4 \pm 1.9$ \\
\hline & \multirow{2}{*}{ PH-AL } & No-stress & $695 \pm 44$ & $154 \pm 15$ & $796 \pm 58$ & $1644 \pm 107$ & $42.3 \pm 1.8$ & $2.2 \pm 0.09$ & $21.8 \pm 1.2$ \\
\hline & & Stress & $516 \pm 52$ & $114 \pm 9$ & $630 \pm 43$ & $1261 \pm 100$ & $38.1 \pm 1.7$ & $1.9 \pm 0.08$ & $14.1 \pm 1.8$ \\
\hline & \multirow{2}{*}{ PH-SS } & No-stress & $482 \pm 51$ & $98 \pm 14$ & $528 \pm 57$ & $1108 \pm 118$ & $43.8 \pm 2.6$ & $2.0 \pm 0.08$ & $27.2 \pm 1.9$ \\
\hline & & Stress & $482 \pm 37$ & $103 \pm 8$ & $535 \pm 44$ & $1120 \pm 85$ & $39.9 \pm 2.3$ & $1.9 \pm 0.07$ & $17.8 \pm 1.9$ \\
\hline \multirow{8}{*}{ P. canariensis } & \multirow{2}{*}{ PC-VI } & No-stress & $634 \pm 62$ & $204 \pm 21$ & $882 \pm 64$ & $1720 \pm 141$ & $70.7 \pm 5.4$ & $2.9 \pm 0.10$ & $37.7 \pm 3.0$ \\
\hline & & Stress & $562 \pm 55$ & $184 \pm 14$ & $954 \pm 55$ & $1700 \pm 112$ & $70.2 \pm 2.9$ & $2.8 \pm 0.10$ & $25.6 \pm 3.2$ \\
\hline & \multirow{2}{*}{ PC-BA } & No-stress & $687 \pm 60$ & $253 \pm 24$ & $1101 \pm 95$ & $2040 \pm 164$ & $68.2 \pm 3.8$ & $2.9 \pm 0.10$ & $34.7 \pm 2.7$ \\
\hline & & Stress & $605 \pm 80$ & $191 \pm 16$ & $918 \pm 66$ & $1715 \pm 145$ & $62.7 \pm 4.3$ & $2.8 \pm 0.10$ & $28.2 \pm 2.9$ \\
\hline & \multirow{2}{*}{ PC-PG } & No-stress & $553 \pm 42$ & $193 \pm 14$ & $825 \pm 61$ & $1571 \pm 111$ & $65.9 \pm 4.8$ & $2.9 \pm 0.07$ & $33.2 \pm 2.6$ \\
\hline & & Stress & $694 \pm 44$ & $195 \pm 13$ & $984 \pm 70$ & $1873 \pm 111$ & $63.6 \pm 3.5$ & $2.8 \pm 0.08$ & $25.5 \pm 2.6$ \\
\hline & \multirow{2}{*}{ PC-TI } & No-stress & $603 \pm 48$ & $227 \pm 17$ & $893 \pm 59$ & $1724 \pm 116$ & $77.4 \pm 4.0$ & $2.8 \pm 0.08$ & $41.8 \pm 2.9$ \\
\hline & & Stress & $642 \pm 55$ & $198 \pm 12$ & $856 \pm 53$ & $1696 \pm 112$ & $73.3 \pm 3.5$ & $2.6 \pm 0.08$ & $27.3 \pm 4.1$ \\
\hline \multirow{8}{*}{ P. pinea } & \multirow{2}{*}{ PA-TO } & No-stress & $783 \pm 49$ & $334 \pm 28$ & $1690 \pm 172$ & $2808 \pm 237$ & $73.7 \pm 2.3$ & $3.1 \pm 0.10$ & $32.9 \pm 1.2$ \\
\hline & & Stress & $708 \pm 63$ & $291 \pm 17$ & $1218 \pm 67$ & $2217 \pm 139$ & $66.8 \pm 1.7$ & $2.9 \pm 0.06$ & $26.5 \pm 1.6$ \\
\hline & \multirow{2}{*}{ PA-TM } & No-stress & $742 \pm 70$ & $299 \pm 29$ & $1367 \pm 131$ & $2409 \pm 226$ & $76.2 \pm 2.9$ & $3.1 \pm 0.17$ & $33.6 \pm 1.7$ \\
\hline & & Stress & $693 \pm 76$ & $270 \pm 18$ & $1198 \pm 82$ & $2160 \pm 169$ & $72.7 \pm 1.9$ & $2.9 \pm 0.06$ & $25.9 \pm 1.3$ \\
\hline & \multirow{2}{*}{ PA-CA } & No-stress & $719 \pm 46$ & $317 \pm 23$ & $1416 \pm 143$ & $2452 \pm 201$ & $80.2 \pm 3.2$ & $3.1 \pm 0.12$ & $37.6 \pm 2.2$ \\
\hline & & Stress & $597 \pm 58$ & $248 \pm 13$ & $1171 \pm 66$ & $2016 \pm 128$ & $67.1 \pm 1.9$ & $2.9 \pm 0.06$ & $27.4 \pm 1.8$ \\
\hline & \multirow{2}{*}{ PA-PL } & No-stress & $727 \pm 48$ & $293 \pm 28$ & $1365 \pm 103$ & $2385 \pm 171$ & $73.3 \pm 2.6$ & $3.0 \pm 0.10$ & $32.8 \pm 2.0$ \\
\hline & & Stress & $691 \pm 89$ & $265 \pm 24$ & $1077 \pm 89$ & $2033 \pm 195$ & $66.1 \pm 2.3$ & $2.7 \pm 0.08$ & $21.4 \pm 1.5$ \\
\hline
\end{tabular}

RDW: root dry weight (mg); SDW: stem dry weight (mg); LDW: leaf dry weight (mg); TDW: total dry weight (mg); H: height (mm); D: diameter $(\mathrm{mm})$; HGD: height growth during drought $(\mathrm{mm})$.

treatment effects. Similar approaches are commonly used in common garden provenance studies in and in most plasticity studies $[6,16,45]$.

The levels of phenotypic change detected in this study with analysis of variance (GLM), angular phenotypic change index (APCI) and allometric analysis were not always coincident. In fact, these analyses evaluate different types of response, which can even be considered as different traits [37]. Both analysis of variance and APCI compare the mean response per species or populations in each environment at a given age. The allometric analysis detects shifts in biomass allocation priorities, independent of plant size, i.e. changes in the allometric trajec- tories of a given species or population, induced in this case, by the water stress.

Regarding the relationship between the observed changes and the phenotypic plasticity of the material under study, if we consider that plasticity must be evaluated in the same material and at similar ontogenic stage, we can conclude that, for comparison at the species level, this is not the case in our study given that sharp differences in ontogeny were found among species at the end of the experiment. However, when comparisons are made at the intraspecific level, both the similarity of ontogenetic scores and the overlapping of plant biomass ranges support the idea that the observed phenotypic changes are in fact plastic responses to an imposed drought stress [32]. 

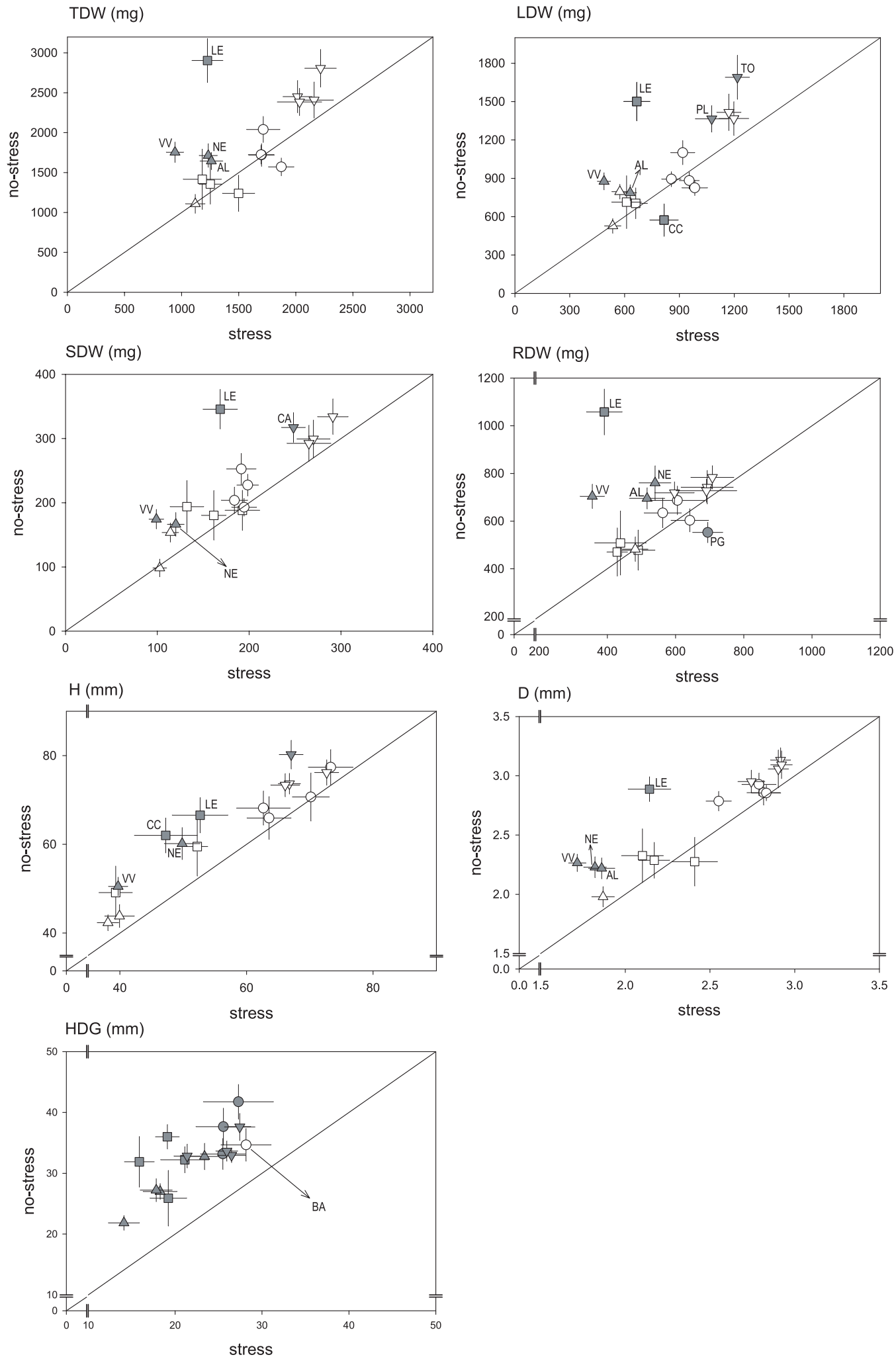

Figure 2. Environment by environment plot for total dry weight (TDW), leaf dry weight (LDW), steam dry weight (SDW), root dry weight (RDW), shoot height (H) and diameter at root collar (D) including the 16 populations studied. Labelling: Squares, Pinus pinaster; up triangles, $P$. halepensis; circles, $P$. canariensis and inverted triangles, $P$. pinea. Dark symbols represent populations with significant differences ( $t$-tests) between phenotypic values in both environments. Bars represent standard errors. Codes for the populations with significant differences follow those included in Table I, excluding the species code. 
PA-TO

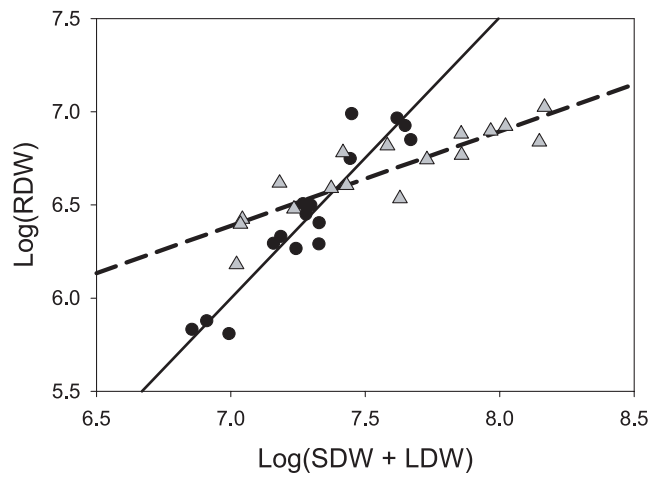

PA-TM

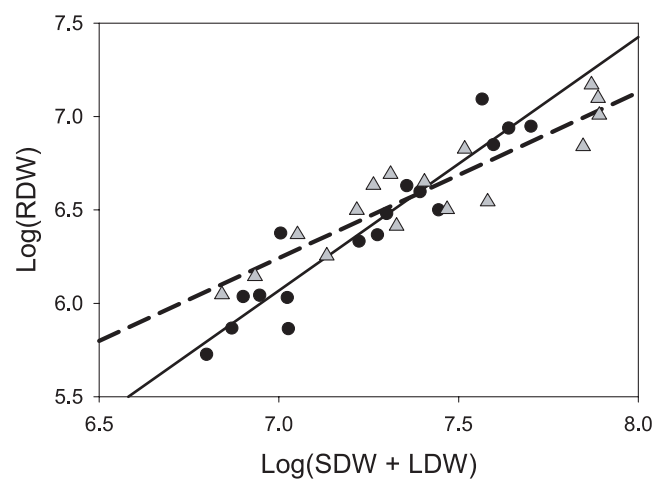

PA-CA

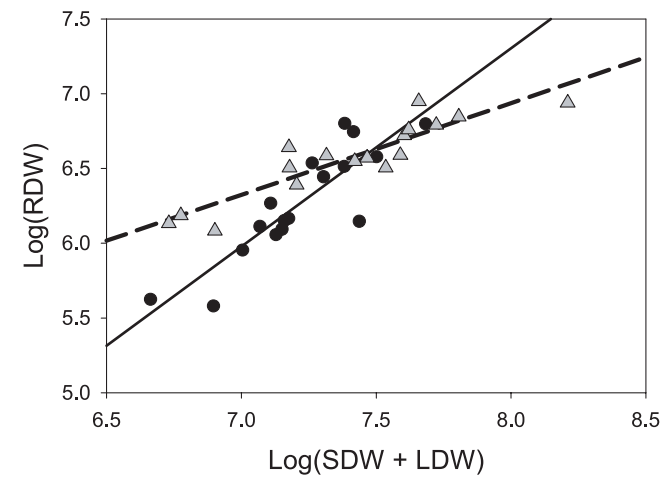

PA-PL

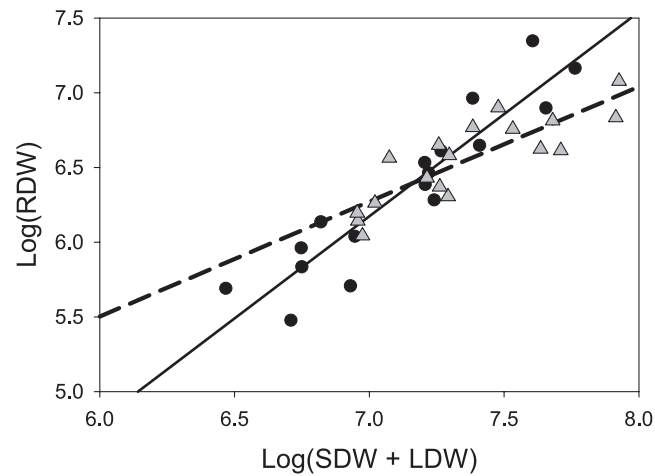

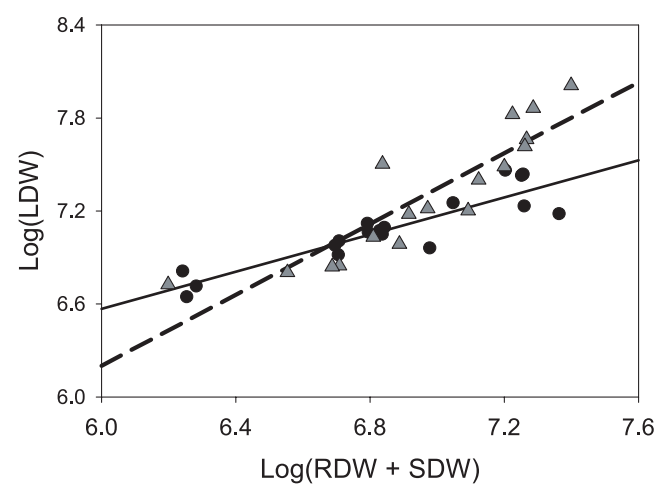
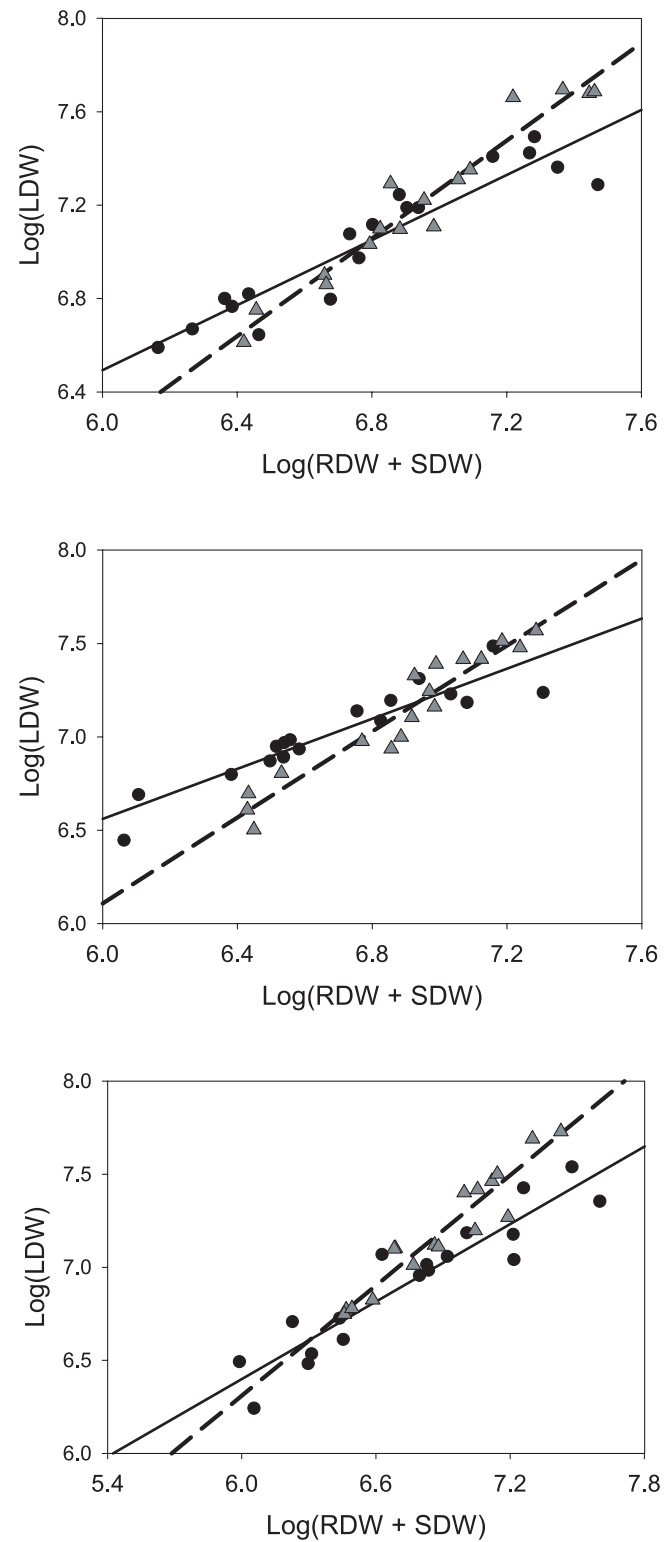

Figure 3. Allometric trajectories for roots (left column) and leaves (right column) of the four populations of Pinus pinea studied. Dots and continuous lines represent stressed plants, triangles and dotted lines represent non-stressed plants. 
Considering all traits together, for the conditions of the experiment, we found a species with scarce phenotypic changes among treatments and populations (Pinus canarien$s i s)$, two species with high population divergence in phenotypic responses among treatments $(P$. pinaster and $P$. halepensis) and a species with virtually no population divergence in phenotypic response to watering regimes $(P$. pinea). Our results confirm that phylogenetically close species may diverge significantly in their response to environmental constraints, when compared under common experimental conditions.

In general, the results obtained in this study agree with those from long term field trials of the same species, which confirms the reliability of the results obtained in short-term tests with artificially imposed stresses. This is the case of Pinus pinea as a whole, as this species presents very low levels of differentiation for phenotypic plasticity (genotype $x$ environment interaction) among populations (Mutke, in prep.) and of populations PR-LE (highly plastic according to [2, 17, 18]), PR-AR, PR-CP, PR-CC [1,2], PH-NE and PH-AL (very plastic and relatively stable, Chambel et al., in prep.). The small phenotypic changes induced by the water stress in Pinus canariensis must be interpreted with caution. Both field and greenhouse studies [8] have demonstrated the high capacity of this species to withstand drought and the existence of intraspecific variation for survival facing drought. It is likely therefore, that the reduction in water supply to $30 \%$ of field capacity was not enough to cause significant developmental changes compared to the other Mediterranean pines. On the other hand, the seedlings of this species showed extremely slow ontogenetic development, with a remarkable absence of axillary meristems throughout the experiment, indicating that the cultivation protocol was ineffective in hastening maturity in this species.

Regarding stone pine (Pinus pinea), the most striking feature is the much higher degrees of allocational plasticity encountered when compared to the changes in growth and total biomass. For the four populations of this species, the allometric trajectories for leaves and roots exhibited significant differences between water regimes and crossed at about mean plant size, leading to a lack of significance of the means comparison tests. Another consequence of this pattern is that only the largest plants behave according to the optimal partitioning theory, shifting allocation to roots when exposed to water stress $[5,41]$. Meaningfully, during the water stress period, the $P$. pinea seedlings, lost water faster (data not shown), indicating higher transpiration rates related to their higher leaf biomass. The fact that, according to this analysis, all populations of Pinus pinea displayed similar and high levels of allocational plasticity (even when their climatic conditions differ sharply) suggests a "generalist" behaviour $[7,41]$, in accordance with the general knowledge on the ecology of this species [14]. Further research is needed to clarify if plasticity is a general feature in Mediterranean stone pine, which would help to interpret the very low levels of both neutral genetic differentiation [15] and quantitative genetic variability within and among populations observed in this species.

Aiming to check the relationship among phenotypic changes and ecological breadth of each species, we plotted the

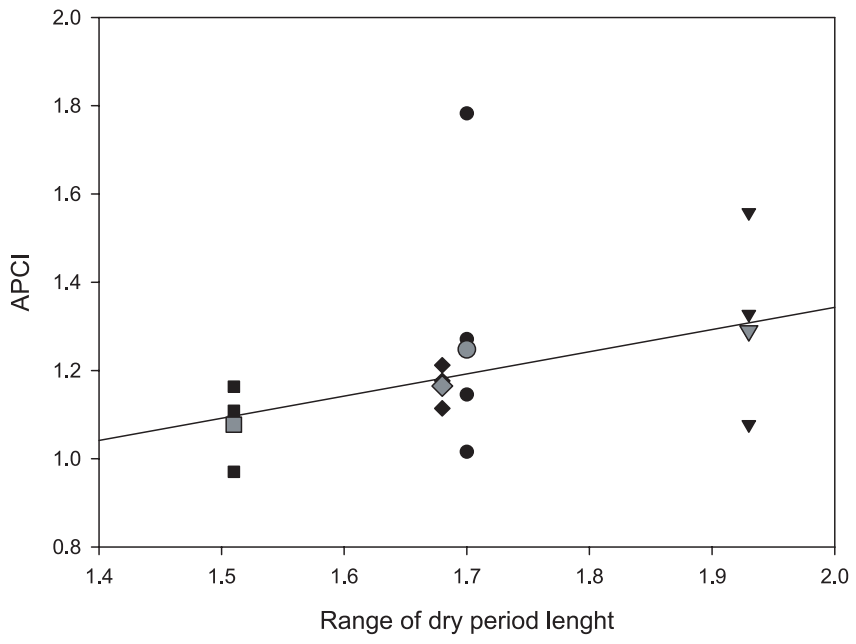

Figure 4. Relationship between phenotypic change (APCI averaged over all variables) and climatic heterogeneity expressed as the range of the dry period length (data obtained from [12] based on Thornwaite's ombro-thermal diagrams) for the Iberian range of each species. Dots: Pinus pinaster; inverted triangles: P. halepensis; squares: $P$. canariensis; diamonds: $P$. pinea. Grey symbols represent average species values.

overall index of phenotypic change (APCI) for each population and each species, versus the ecological breadth in water availability per species, represented by the range of the summer drought length (Fig. 4). This last parameter is an easy-to-obtain, good discriminant ecological parameter when comparing Mediterranean pines [14]. Meaningfully, there is a positive relationship between both parameters: the spatial heterogeneity within each species' range and its overall phenotypic change. This result gives a similar picture as that reported for the Mediterranean Quercus coccifera regarding shade tolerance [3], although at a much greater spatial scale. However, as already stated, defining behaviour in terms of phenotypic change facing drought at the species level, seems worthwhile in Pinus pinea, but worthless in Pinus pinaster due to the huge divergence among populations for this character.

By contrast, a relationship between mean phenotypic change (APCI) per species and its intraspecific variation is not evident. The four species studied displayed extremely different phenotypic responses to a common drought stress both at the inter- and intra-specific level, indicating different adaptive strategies. The results of the present study indicate that ontogeny should be taken into account, beyond being merely estimated through plant size, when comparing seedlings of these species at an early developmental stage. Moreover, the different levels of phenotypic change described for the four Mediterranean pine species must be combined to fully understand the adaptive mechanisms allowing them to cope with changing environments.

Acknowledgements: We acknowledge I. Aranda for advice on the water stress treatment and N. Godoy, P. Pereira, S. Herrera, F. del Caño, A. Piñera, D. Barba, R. Arranz and J. Alonso for technical assistance. Special thanks to P.M. Smouse, S. Mutke, F. Valladares 
and the reviewers for their helpful critical comments. This study was supported by the project INIA-DGB CC03-048, and a grant from the AECI to the first author

\section{REFERENCES}

[1] Alía R., Gil L. Pardos J.A., Performance of 43 Pinus pinaster Ait. Provenances on 5 locations in central Spain, Silvae Genet. 44 (1995) $75-81$.

[2] Alía R., Moro J. Denis J.B., Performance of Pinus pinaster provenances in Spain: interpretation of the genotype by environment interaction, Can. J. For. Res. 27 (1997) 1548-1559.

[3] Balaguer L., Martinez-Ferri E., Valladares F., Perez-Corona M.E., Baquedano F.J., Castillo F.J. Manrique E., Population divergence in the plasticity of the response of Quercus coccifera to the light environment, Funct. Ecol. 15 (2001) 124-135.

[4] Barbéro M., Loisel R., Quézel P., Richardson D.M., Romane F., Pines of the Mediterranean basin, in: Richardson D.M. (Ed), Ecology and biogeography of Pinus, Cambridge University Press, 1998 pp. 153-170.

[5] Bloom A.J., Chapin F.S., Mooney H.A., Resource limitation in plants - an economic analogy, Annu. Rev. Ecol. Syst. 16 (1985) 363-392.

[6] Bouvet J.-M., Vigneron P., Saya A., Phenotypic plasticity of growth trajectory and ontogenic allometry in response to density for eucalyptus hybrid clones and families, Ann. Bot. 96 (2005) 811-821.

[7] Bradshaw A.D., Evolutionary significance of phenotypic plasticity in plants, Adv. Genet. 13 (1965) 115-155.

[8] Climent J., Gil L., Pérez E., Pardos J.A., Efecto de la procedencia en la supervivencia de plántulas de Pinus canariensis Sm. en medio árido., Invest. Agr. Sist. Recur. For. 11 (2002) 171-180.

[9] Coleman J.S., McConnaughay K.D.M., Ackerly D.D., Interpreting phenotypic variation in plants, Trends Ecol. Evol. 9 (1994) 187191.

[10] Curt T., Coll L., Prévosto B., Baladier P., Kunstler G., Plasticity in growth, biomass allocation and root morphology in beech seedlings as induced by irradiance and herbaceous competition, Ann. For. Sci 62 (2005) 51-60.

[11] Chapin F.S., Bloom A.J., Field C.B., Waring R.H., Plant responses to multiple environmental factors, BioScience 37 (1987) 49-57.

[12] Evans G.C., The quantitative analysis of plant growth, University of California Press, Berkeley, California, USA, 1972.

[13] Galloway L.F., Maternal effects provide phenotypic adaptation to local environmental conditions, New Phytol. 166 (2005) 93-100.

[14] Gandullo J., Sánchez Palomares O., Estaciones ecológicas de los pinares españoles, ICONA, Ministerio de Agricultura, Pesca y Alimentación, Madrid, 1994.

[15] Gómez A., Aguiriano E., Alia R., Bueno M.A., Análisis de los recursos genéticos de Pinus pinea L. en España mediante microsatélites del cloroplasto, Invest. Agrar. Sist. Recur. For. 11 (2002) $145-154$.

[16] Griffith T.M., Sultan S.E., Shade tolerance plasticity in response to neutral vs. green shade cues in Polygonum species of contrasting ecological breadth, New Phytol. 166 (2005) 141-148.

[17] Harfouche A., Baradat P., Durel C.E., Variabilité intraspécifique chez le pin maritime (Pinus pinaster Ait.) dans le sud-est de la France. I. Variabilité des populations autochtones et des populations de l'emsemble de l'aire de l'espèce, Ann. Sci. For. 52 (1995) 307-328.

[18] Hopkins E.R., Butcher T.B., Provenance comparisons of Pinus pinaster Ait. in western Australia, CALMScience 1 (1993) 55-105.

[19] Huber H., Lukács S., Watson M.A., Spatial structure of stoloniferous herbs: an interplay between structural blue-print, ontogeny and phenotypic plasticity, Plant Ecol. 141 (1999) 107-115.
[20] Johnsen O., Fossdal C.G., Nagy N., Molmann J., Daehlen O.G. Skroppa T., Climatic adaptation in Picea abies progenies is affected by the temperature during zygotic embryogenesis and seed maturation, Plant. Cell Environ.

[21] Jones C.S., An essay on juvenility, phase change and heteroblasty in seed plants, Int. J. Plant Sci. 160 (1999) S105-S111.

[22] Klaus W., Mediterranean pines and their history, Plant Syst. Evol. 162 (1989) 133-163.

[23] Langle O., Two hundred years genecology, Taxon 20 (1971) 653-722.

[24] Lascoux D.M., Kremer A., Dormling I., Growth and phenology of 1-year-old maritime pine (Pinus pinaster) seedlings under continuous light: implications for early selection, Can. J. For. Res. 23 (1993) 1325-1336.

[25] Lester D.T., Developmental patterns of axillary meristematic activity in seedlings of Pinus, Bot. Gaz. 129 (1968) 206-210.

[26] López G.G., Kamiya K., Harada K., Phylogenetic relationships of Diploxylon pines (Subgenus Pinus) based on plastid sequence data, International, J. Plant Sci. 163 (2002) 737-747.

[27] Merilä J., Laurila A., Lindgren B., Variation in the degree and costs of adaptive phenotypic plasticity among Rana temporaria populations, J. Evol. Biol. 17 (2004) 1132-1140.

[28] Meyers L.A., Bull J.J., Fighting change with change: Adaptive variation in an uncertain world, Trends Ecol. Evol. 17 (2002) 551-557.

[29] Müller I., Schmid B., Weiner J., The effect of nutrient availability on biomass allocation patterns in 27 species of herbaceous plants, Perspect. Plant Ecol. Evol. Syst. 3 (2000) 115-127.

[30] Nguyen A., Dormling I., Kremer A., Characterization of Pinus pinaster seedling growth in different photoperiods and thermoperiods in a phytotron as a basis for early selection, Scand. J. For. Res. 10 (1995) 129-139.

[31] Pigliucci M., Schlichting C.D., Reaction norms of Arabidopsis. IV. Relationships between plasticity and fitness, Heredity 76 (1996) 427-436.

[32] Poorter H., Nagel O., The role of biomass allocation in the growth response of plants to different levels of light, $\mathrm{CO} 2$, nutrients and water: a quantitative review, Aust. J. Plant Physiol. 27 (2000) 595-607.

[33] Preston K.A., Ackerly D.D., The evolution of allometry in modular organisms, in: Pigliucci M., Preston K.A. (Eds.), Phenotypic Integration: studying the ecology and evolution of complex phenotypes, Oxford University Press, 2003.

[34] Scheiner S.M., Genetics and evolution of phenotypic plasticity, Annu. Rev. Ecol. Syst. 24 (1993) 35-68.

[35] Scheiner S.M., Lyman R.F., The genetics of phenotypic plasticity. II. Response to selection, J. Evol. Biol. 4 (1991) 23-50.

[36] Schlichting C.D., The evolution of phenotypic plasticity in plants, Annu. Rev. Ecol. Syst. 17 (1986) 667-693.

[37] Schlichting C.D., Pigliucci M., Phenotypic evolution - A reaction norm perspective, Sinauer Associates, Sunderland, MA, 1998.

[38] Shelbourne C.J.A., Genotype-environmentinteraction: its study and its implications in forest tree improvement, in SABRAO Joint Symposium, 1972, Tokyo, Government Forest Experiment Station.

[39] Strand J.A., Weisner S.E.B., Phenotypic plasticity - contrasting species-specific traits induced by identical environmental constraints, New Phytol. 163 (2004) 449-451.

[40] Sultan S.E., Evolutionary implications of phenotypic plasticity in plants, Evol. Biol. 21 (1987) 127-178.

[41] Sultan S.E., Phenotypic plasticity for plant development, function, and life-history, Trends Plant Sci. 5 (2000) 537-542.

[42] Sultan S.E., Phenotypic plasticity in plants: a case study in ecological development, Evol. Dev. 5 (2003) 25-33.

[43] Tapias R., Climent J., Pardos J.A., Gil L., Life histories of Mediterranean pines, Plant Ecol. 171 (2004) 53-68. 
[44] Valladares F., Balaguer L., Martinez-Ferri E., Perez-Corona M.E., Manrique E., Plasticity, instability and canalization: is the phenotypic variation in seedlings of sclerophyll oaks consistent with the environmental unpredictability of Mediterranean ecosystems? New Phytol. 156 (2002) 457-467.

[45] Valladares F., Dobarro I., Sanchez-Gomez D., Pearcy R.W. Photoinhibition and drought in Mediterranean woody saplings: scaling effects and interactions in sun and shade phenotypes, J. Exp. Bot. 56 (2005) 483-494.

[46] Valladares F., Wright S.J., Lasso E., Kitajima K. Pearcy R.W., Plastic phenotypic response to light of 16 congeneric shrubs from a Panamanian rainforest, Ecology 81 (2000) 1925-1936.

[47] Van Eeuwijk F.A., Malosetti M., Yin X., Struik P.C., Stam P., Statistical models for genotype by environment data: from conventional ANOVA models to eco-physiological QTL models. Austr. J. Agric. Res. (2005) 12.

[48] Via S., Adaptive phenotypic plasticity - Target or by-product of selection in a variable environment, Am. Nat. 142 (1993) 352-365.

[49] Wang G.G., Bauerle W.L., Effects of light intensity on the growth and energy balance of photosystem II electron transport in Quercus alba seedlings, Ann. For. Sci. 63 (2006) 111-118.

[50] Weiner J., Allocation, plasticity and allometry in plants, Perspect. in Plant Ecol. Evol. Syst. 6 (2004) 207-215.

[51] Wells C., Pigliucci M., Adaptive phenotypic plasticity: the case of heterophylly in aquatic plants, Perspect. Plant Ecol. Evol. Syst. 3/1 (2000) 1-18.

[52] Williams C.G., The influence of shoot ontogeny on juvenile-mature correlations in loblolly pine, For. Sci. 33 (1987) 411-422. 